\title{
Discursos, narrativas y percepciones entre los y las niñas de la calle en torno a su huida*
}

\author{
María Espinosa Spínola
}

Mi intención al escribir este artículo es mostrar las interpretaciones que los jóvenes en la ciudad de México hacen de su salida a la calle a partir de un estudio etnográfico. Se exponen las decisiones que tomaron a partir de la lógica que subyace a la construcción de las relaciones materno-filiales, aquellas escenas de violencia dentro de sus familias que los chicos sufrían de diversas maneras y los significados que le otorgaban a la calle. La formulación se hará a partir de las percepciones de los chicos, de sus percepciones, de cómo vivieron una realidad que los situaba ante dilemas y a partir de los que actuaron como agentes sociales. Esto me lleva a reconocerlos como actores protagonistas en su desarrollo y con agencia social.

PALABRAS CLAVE: etnografía, infancia de la calle, maternidad, representaciones de género, violencia

\section{Discourses, Narratives and Perceptions among Street Children in their Runaway}

Based on an ethnographic research carried out with street children in Mexico City, I intend to show the interpretations that boys and girls made of their going out in the street. They took decisions based on the logic of the building of mother-child relationships, on the scenes of violence within their families the children suffered in different manners, and on the meanings provided by the street. I will explain their perceptions about the reality they lived a reality that place them before a series of dilemmas and from the manner in which social agents acted. That's why I see them as main actors in their development and with social agency.

KEYWORDS: ethnography, street childhood, motherhood, gender representations, violence.

MARÍa EsPinosa SPÍnOla: Instituto de Estudios de la Mujer, Universidad de Granada, Granada, España mspinol@correo.ugr.es

Desacatos, núm. 40, septiembre-diciembre 2012, pp. 97-110

Recepción: 16 de agosto de 2010 / Aceptación: 29 de abril de 2012

\footnotetext{
* Este artículo es resultado de parte del trabajo realizado para el Proyecto I+D+I: FEM 2009-10982 "Etnografiando prácticas de resistencia. Escenarios, eventos y narrativas en la construcción de ciudadanía, dirigido por Carmen Gregorio Gil y financiado por el Ministerio de Ciencia e Innovación.
} 


\section{TODO NECESITA UN CONTEXTO}

$\mathrm{A}$ partir de la tesis doctoral en antropología social realizada sobre niños y niñas de la calle en México, Distrito Federal, analizo las interpretaciones que los chicos y chicas en situación de calle daban a la hora de explicar los motivos de su salida o huida a la calle. Mi interés por el tema surgió a partir de tres estancias de investigación en la ciudad de México en 2000, 2003 y 2009. Durante esos años colaboré en dos ocasiones como educadora en hogares de acogida con adolescentes de ambos sexos que habían vivido en la calle y posteriormente trabajé como educadora de calle en la zona poniente de la ciudad con la institución de asistencia privada San Felipe de Jesús. Los métodos utilizados en la investigación han sido cualitativos. Considero que a partir de éstos puede comprenderse mejor la realidad de los y las sujetos inmersos en ella, que tienen una existencia propia como resultado de un proceso
La metodología empleada ha sido la observación participante y las entrevistas de profundidad. He usado la observación participante con la intención de describir y analizar aspectos relacionados con las formas en las que viven estos jóvenes tanto en los hogares como en la calle y la forma en que se relacionan u organizan entre sí. Interpreto la observación participante como eje central de la práctica etnográfica como mi disposición al extrañamiento para "convertir en objeto de indagación lo que se nos muestra como 'normal' o 'natural' en el curso ordinario de la vida” (Gregorio, 2006a: 15-16), en este caso, de los niños en situación de calle. He realizado la observación in situ de las prácticas de los menores en los lugares en los que tuve la oportunidad de colaborar como educadora, por tanto, son tres los momentos en los que llevé a cabo la observación.

Los tres primeros meses colaboré en el Hogar Sol. Lo integraban 15 adolescentes hombres, dos educadores o "tíos" trabajadores de la institución y dos extranjeras, mi compañera Alicia y yo. La segunda estancia de investigación, también de tres meses, fue en el Hogar Crepúsculo para niñas y adolescentes mujeres. La tercera estancia de investigación tuvo una duración de cuatro meses. Los lugares de observación fueron varios, aquellos en los que la institución con la que colaboraba como educadora de calle intervenía. Uno de ellos era el punto de pernocta situado a la salida de la estación del Metro Observatorio, en el parque que se encuentra al final de los puestos de comercio ambulante que rodean la estación. Acudía a este lugar con dos educadores más, tres mañanas por semana, para hablar con los chicos, saber cómo les había ido en el trabajo, platicar sobre cómo se encontraban, qué pensaban hacer o si habían tenido problemas durante la noche. También jugábamos con ellos e intentábamos convencerlos de que acudiesen al Centro de Día Matlapa Observatorio de la misma fundación, que se ubicaba a unos 100 metros del punto de pernocta.

Hubo otros lugares de observación, como los puntos de pernocta de las bandas de Las Bombas, en Tacubaya, y el de Barranca del Muerto, ubicado justo a la salida de la estación del metro del mismo nombre. Las entrevistas diseñadas en el trabajo de campo fueron principalmente abiertas y semiestructuradas. Grabé en total 26, diez con niñas y 16 con niños, todos y todas entre los diez y 18 años de edad. El objetivo era conocer sus percepciones sobre aquellos asuntos en los he centrado el interés de mi investigación, cuestión que me lleva a mirarlos como productores de significados y, por tanto, con pensamiento propio. ${ }^{1}$

\footnotetext{
${ }^{1}$ Sobre la importancia de rescatar las voces de niños y niñas, Milstein (2006: 2) apunta que las investigaciones antropológicas que recogen sus percepciones son escasas, de manera tal que las historias que nos narran no son valoradas debidamente, siendo que se trata en última instancia de vivencias que modelan las experiencias vividas que se están etnografiando. Es de llamar la atención, como sostiene la autora, si tenemos en cuenta la importancia de los chicos y chicas en los procesos de reproducción cultural.
} 


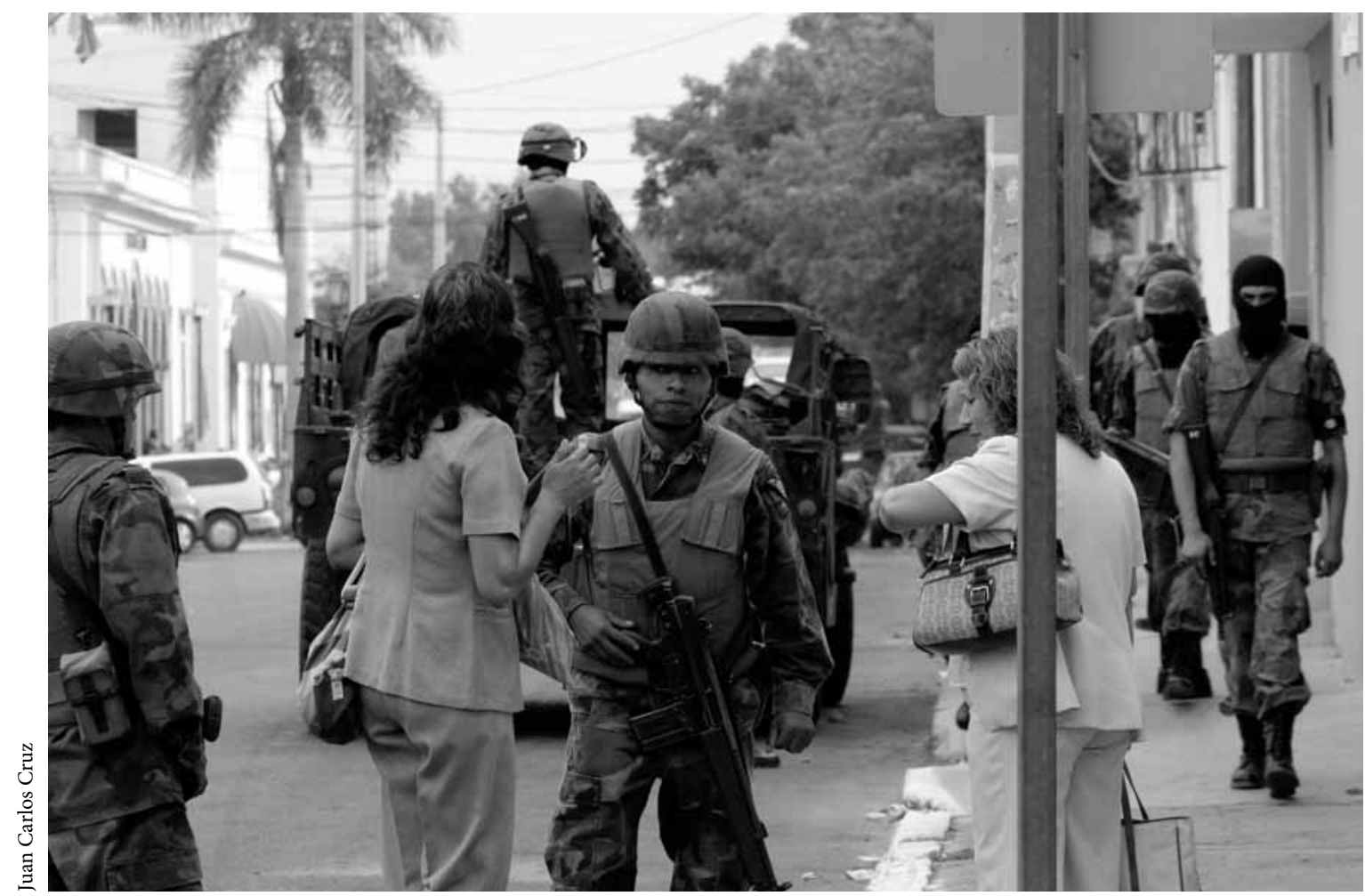

A partir de 2008, el gobierno federal implementó operativos conjuntos para patrullar las calles con miles de militares, agentes federales y marinos en varios estados del país con el fin de combatir el narcotráfico, 2008.

Este tipo de entrevistas me permitió obtener información novedosa y relevante que incluí en entrevistas posteriores. Ha sido una herramienta que definí durante las estancias, conforme iba conociendo de forma más detallada la realidad de los sujetos. En un primer momento las entrevistas tenían el objetivo de recoger información sobre cuestiones muy amplias que distribuí en función de dos momentos por los que habían pasado todos los niños y niñas: antes de salir a la calle y una vez en ella. En relación con el primer momento, la vida en sus hogares de origen, me interesaba conocer los lugares en los que nacieron y los antecedentes familiares, como tipología de familia, si era reconstituida o monoparental. Pregunté por el número de miembros de la unidad familiar, funciones y tareas según el género, trabajos que realizaban sus genitores, trabajo de los menores en caso de hacerlo y cómo era la relación entre los miembros de la familia. En la segunda parte de la entrevista los interrogantes tenían la finalidad de recoger información sobre los motivos por los que habían abandonado la unidad familiar. En un tercer apartado, en correspondencia con el periodo que habían pasado en calle, traté cuestiones relevantes para mí, como la edad de salida, el tiempo vivido en calle, los lugares de pernocta, con quién lo hacían, las relaciones entre los integrantes de las bandas y los significados que le otorgaban a la calle.

\section{El contexto}

Para comprender las percepciones de los niños y niñas con los que tuve la oportunidad de trabajar y la manera de vivir la realidad ante la que decidieron 
actuar, considero imprescindible contextualizar la situación de partida de los menores entrevistados. No pretendo generalizar, sino mostrar una de las posibles interpretaciones sobre la realidad estudiada. Una constante en las familias de las que provenían los niños y niñas entrevistados es el abandono del hogar por parte del padre biológico, siendo las madres las que asumen el cuidado de los hijos. A menudo la causa del abandono era la unión del padre con otra mujer con la que, a su vez, procreaba más hijos. La imposibilidad de los hombres de mantener a todos sus hijos, aparentemente favoreció la evasión de las responsabilidades que acompañaban la paternidad biológica. Tras el abandono, las mujeres habitualmente se unieron con otros hombres. ${ }^{2}$ Los menores pasaron de una familia monoparental a una "reconstituida". Esta situación fue percibida y analizada minuciosamente por los niños y niñas, quienes construyeron una visión particular sobre las relaciones de sus progenitores y encontraban una serie de explicaciones sobre las decisiones que llevaban a sus padres y madres a mantener o romper las uniones.

Desde la perspectiva de los niños y las niñas, las diversas uniones de sus mamás no respondían a sus necesidades como madres y esposas, es decir, el "deber ser" no correspondía con la realidad, ya que aunque muchas mujeres intentaban sustituir al padre biológico, buscaban un apoyo económico y emocional en la nueva unión y con frecuencia sus nuevas parejas no respondían a tales "deseos": no asumían el rol de proveedor, padre y esposo. Los chicos eran conscientes de que la nueva relación era más una creencia, una atribución social de orden simbólico, que una realidad. En sus discursos los niños se lamentaban continuamente de que en sus hogares las madres eran las que se preocupaban por obtener los recursos económicos, de que los padres o padrastros eran infieles y de que las relaciones entre

\footnotetext{
${ }^{2}$ Una práctica extendida en Latinoamérica son los "matrimonios seriados": mujeres que una vez que se quedan solas se unen a otros hombres, ya que la condición de "mujer sola" con frecuencia tiene repercusiones (González de la Rocha, 1999).
}

los padrastros y los hijastros o hijastras estaban marcadas en general por los conflictos, con lo cual el deseo de que la nueva pareja sustituyese al padre de los chicos, en el sentido de ser una figura de referencia o modelo para ellos, tampoco se hacía realidad.

Esta situación estaba tan presente en el imaginario de los chicos y chicas que muchos de ellos al nombrar a sus madres y a las mujeres utilizaban el calificativo "p y p". Me llamó mucho la atención escuchar las constantes alusiones que hacían los chicos del Hogar Sol a las madres calificándolas como "p y p": "putas y pendejas". Después de conocer el significado de este apelativo, los niños me explicaron por qué tenían tales ideas. Las respuestas que me dieron ponían de manifiesto la creencia de que sus madres eran unas "putas" porque mantenían relaciones sentimentales y/o sexuales con distintos hombres una vez finalizada la unión con el padre biológico. Las llamaban "pendejas" porque ellas eran las encargadas principales del trabajo productivo, las únicas de ocuparse del reproductivo y porque, en ocasiones, eran maltratadas por sus compañeros.

Así lo relataba Josué una tarde que salimos del Hogar Sol a dar un paseo: "Aquí las mujeres —casi todas- son bien culeras, unas putas porque andan con unos y con otros, $y$ unas pendejas porque al final eligen a hombres bien pedos que se aprovechan de ellas". Por consiguiente, en el imaginario de los niños y las niñas existían dos formas de concebir a las mujeres. Por un lado se encontraban las "buenas mujeres" y "buenas madres", que eran para los chicos y chicas aquellas que respondían a atributos como la bondad, el sacrificio, la dedicación, la abnegación y la ternura. En el lado opuesto, como señala Amuchástegui (1996: 155), se encontraban las mujeres cuya sexualidad no tenía fines reproductivos ${ }^{3} y$ por tanto eran consideradas "malas mujeres" y "malas madres".

\footnotetext{
${ }^{3}$ Tareas de reproducción consideradas como principales y exclusivas de las mujeres que han sido fuertemente cuestionadas por autoras como Simone de Beauvoir, Nancy Chodorov, Adrianne Rich y Silvia Vegetti, entre otras, al reflexionar sobre su función dentro del orden patriarcal (Cid, 2002: 11).
} 


\section{TOMANDO DECISIONES}

Los niños y niñas entrevistados hacían diversas interpretaciones sobre las decisiones que los llevaron a huir de sus hogares. He identificado tres a partir de sus testimonios. La primera aparece estrechamente relacionada con la construcción de las relaciones materno-filiales y las expectativas que se depositan en ellas, la segunda tiene que ver con la manera de vivir las escenas de violencia que con frecuencia presidían sus hogares, y la última emerge a partir del valor y significado que niños y niñas asignaban al espacio "calle".

\section{Expectativas de las relaciones materno-filiales}

Entiendo por relaciones materno-filiales el conjunto de imágenes, prácticas y sentimientos que se depositan sobre las relaciones entre madres e hijos (Del Valle, 2002b). Estas relaciones están marcadas por un amor que se presenta naturalizado al ser asociado con la concepción y que conlleva generosidad sin límites, incondicionalidad, protección, sacrificio y abnegación. Me refiero a los significados culturales, sociales e ideológicos que nos muestran las representaciones sociales sobre las mujeres como equivalentes a "madres" y que con frecuencia los niños y niñas reproducían en sus discursos. Las mujeres son imaginadas con atributos como la ternura, la pureza y la decencia. En este sentido, Amuchástegui sostiene que en ellas la belleza se relaciona con la espiritualidad, el alma y la bondad. Son merecedoras del matrimonio y de la maternidad, ${ }^{4}$ función para la cual están destinadas y sin la que no se les reconoce el estatus de sujeto (Amuchástegui, 1996: 155).

\footnotetext{
${ }^{4}$ En relación con esta idea, Rocha (1999: 16) plantea: "La mujer como esposa y madre es el punto de partida y llegada al que debe aspirar toda mujer: ser nieta, esposa, madre, abuela, son etapas en el ciclo de su vida que conducen a un destino encerrado en el 'eterno femenino"'.
}

La maternidad ${ }^{5}$ como función esencial de las mujeres está muy presente en la sociedad mexicana y es reforzada mediante el mito de la "madre mexicana", cuyo culto inició en 1922, que venera a un tipo de mujer sin control sobre su cuerpo ni sobre su vida, consagrada a la vida de los otros, con la abnegación y el sacrificio como los ejes principales sobre los que se articula su representación. En palabras de Thurer:

La buena madre de la modernidad industrializada, idolatrada por su esencia altruista de cuerpo para otros, su carácter hogareño, la "mártir maternal", enajenada de su propia sexualidad en nombre del instinto materno (Thurer, 1994: 194, citado en Maier, 1999: 100).

Esta visión de la función reproductora de las mujeres y los significados de la "madre mexicana" se ven reflejados en la siguiente nota de prensa publicada en el periódico capitalino Excélsior el primer Día de las Madres en México. Se exalta la importancia de la reproducción, al mismo tiempo que se exponen con claridad los atributos que se considera debe poseer toda "buena madre" y que aún están presentes en el imaginario colectivo:

El 10 de mayo es el Día de las Madres, homenaje a las mujeres que han cumplido su santa misión llenas de sacrificios y dolores, con entereza, abnegación y ternura. Exprese usted toda su gratitud en este día a quien le dio el ser. Fragrantes flores y castos besos coronarán hoy las cabezas de las madres mexicanas (Excélsior, 10 de mayo de 1922, citado en Maier, 1999: 97).

Estas representaciones sobre la figura maternal aparecían en los discursos de niños y niñas al explicar los motivos por los que abandonaban el hogar. Es decir, los chicos y chicas relacionaban y explicaban de manera recurrente su salida a la calle a partir de las expectativas que se derivaban de las relaciones

\footnotetext{
${ }^{5}$ Véanse Blanco et al. (2002) y Lamas (1996).
} 
materno-filiales y los cuidados que para ellos conllevaba el amor materno. Culpaban con crueldad a sus madres porque no respondían a las creencias y percepciones que le atribuían a toda "buena madre", y cuando sentían que sus progenitores, sobre todo sus mamás, no les daban el cariño y atención que necesitaban. Estas narrativas ponen de manifiesto, como sugiere Del Valle, la fuerza que cobran los mandatos de género y su "impacto en la creación de modelos de padres, madres, esposas, mujeres y hombres que se reproducen en la socialización temprana” (Del Valle, 2010: 311). Así me lo contaba Ricardo cuando le pregunté por los motivos que lo llevaron a tomar la decisión de salir a la calle:

Me salí porque no encontraba el afecto, no encontraba el amor, el cariño de un padre, de una madre dentro de mi casa, por eso me salí. Antes yo decía, a todos los chavillos de la calle, les preguntabas “ipor qué te habías salido?". Y te decían: "Es que mi mamá me pegaba, mi papá me maltrataba, me hacían esto, me hacían el otro". Y eso es lo que yo decía. Ahora te puedo decir que no es cierto, que no es cierto. Fíjate que alguno, la mayoría, se sale por falta de cariño, por falta de cariño de sus papás, con lo mismo de que son pobres se van a trabajar sus papás y sus mamás no tienen el tiempo para decirte: “¿Cómo estás hijo? ¿Cómo te fue en la escuela? Pásame tus libretas para ver cómo estás", o algo así por el estilo. Yo me salí por la falta de un afecto de una mamá, de un papá, que me quisiera, que me alentara, porque tenían cosas qué hacer. Más bien, por falta de cariño de mi mamá, porque el otro pendejo yo no sé qué onda (Ricardo, entrevista).

Las expectativas depositadas en el vínculo madrehijo tampoco se hacían realidad desde el momento en que las mamás no los cuidaban ni los protegían ante la violencia que presidía las relaciones entre los hijos, las hijas y los padrastros, sobre todo cuando interpretaban que sus madres no mediaban ante esa violencia. La necesidad de protección también era

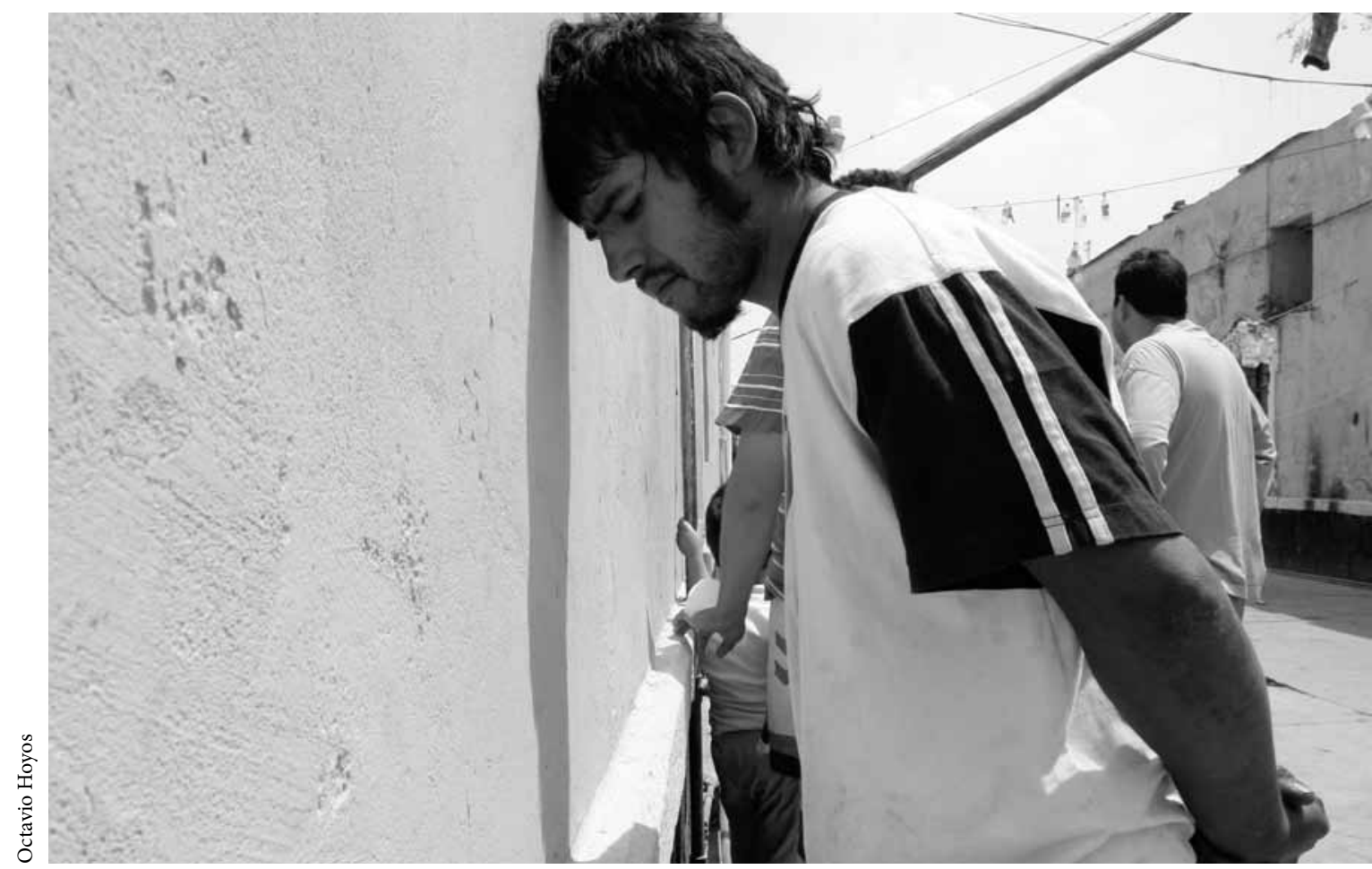

Aprehensiones a narcomenudistas en el Barrio de Tepito durante un operativo policiaco, 2007. 
reclamada por niños y niñas. Guadalupe lo expresaba en la entrevista. Tras encontrar a su mamá en el Distrito Federal, permaneció una temporada conviviendo con su padrastro, su madre y su hermana. Durante ese tiempo, me contaba, la convivencia fue muy difícil porque el padrastro no la aceptaba, no la quería y la maltrataba. Le decía continuamente que se fuera de la casa. En muchas ocasiones su mamá estaba delante y no mediaba, situación que le hacía dudar del cariño de su madre. Se preguntaba si su mamá la quería o no, una contradicción constante que la atormentaba, según me confesó, entre llantos, en la entrevista:

Me aferré a mi mamá y decía: "es que mi mamá sí me quiere". Ahora me doy cuenta de que no, porque si me hubiera querido no estaría con ese desgraciado. ¡Ella no se movía cuando me maltrataba el hijo puta! Cuando me corría de la casa y no me abría la puerta. Me decía: “Pinche puta desgraciada, lárgate de la casa!” (Guadalupe, entrevista).

También la violencia sexual sufrida por las niñas aparecía en sus discursos como factor que intervenía en su salida. Además, interpretaban que sus madres consentían esa violencia y aun sabiéndolo permanecían unidas a los sujetos que la ejercían: sus padrastros. Claudia me contaba que desde que era muy pequeña su mamá se juntó con otro hombre y que éste abusaba de ella frecuentemente desde que tenía 12 años. Claudia, sin embargo, apenas hasta hace un año que decidió ir a visitar a su madre supo que ese hombre era su padrastro, puesto que su mamá siempre le dijo que era su padre. Los motivos por los que Claudia decidió salir a la calle fueron dos: en primer lugar, los continuos abusos de su padrastro y, en segundo lugar, porque interpretaba que su mamá cedió ante esa violencia, pues a pesar de que lo denunció reanudó la relación con su padrastro:

- Por una parte veo bien que mi madre se haya juntado con otro hombre, pero por otra parte no. Por lo que me hizo [silencio].
- ¿Qué te hizo? - pregunto.

- Abusó de mí a los 12 años y me pegaba. Además, mi mamá lo sabía, pero no hizo nada, bueno, al principio le pusimos una denuncia, pero al tiempo regresó con él y yo me salí a la calle (Claudia, entrevista).

Las expectativas sobre las relaciones materno-filiales tampoco se cumplían cuando, tras la ruptura de la relación matrimonial, las mamás no se hacían cargo del cuidado de los hijos. Cuando la mamá de Víctor abandonó a su padre biológico para unirse a otro hombre no se llevó a todos sus hijos con ella, sólo se hizo cargo del más pequeño, y él y sus hermanas quedaron al cuidado de su padre. Víctor le reprochaba esto a su madre, pues entendía que su obligación era cuidar de ellos. Me había explicado instantes antes que su mamá le fue infiel a su padre, se veía a solas con otro hombre hasta que un día el papá los encontró y la madre abandonó definitivamente al papá para irse a vivir con ese hombre, llevándose sólo al hermano más pequeño. Víctor percibía que la ruptura de vínculos por parte de su mamá y el hecho de que no se hiciera cargo de ellos fueron la causa de su huida a la calle, algo que le reprochó cuando decidió ir a visitarla. Para este chico las consecuencias de esa unión fueron determinantes, ya que si ella hubiese permanecido con el papá, "estuviera ahí con ellos, contento, felices y a lo mejor tuviera hasta mi terreno y hasta fuera casado o juntado":

Cuando fui le reclamé a mi jefa. Le dije: “¿Sabes qué? La neta, te tengo rencor todavía” ¡ $Y$ sí, le dije sus verdades a mi mamá! Le dije que le tenía rencor a ella. Le dije: "Si no la hubieras regado ahí con separarte de mi jefe, la neta, pues no me hubiera ido". A lo mejor ni conociera México y estuviera ahí con ellos, contento, felices y a lo mejor tuviera hasta mi terreno y hasta fuera casado o juntado.

Todo esto se lo reclamé a mi mamá y hasta estuvo llorando y me dijo: “¡No, hijo...!". Yo le dije: “Nada más por su culpa, jefa, la neta, hasta dónde fui a conocer la droga más fuerte allí en México". Le digo: "Pues ando tirado en eso y hasta estuve en la cárcel". Y se me puso a llorar más mi jefa (Víctor, entrevista). 
Por último, las creencias depositadas en las relaciones materno-filiales tampoco se hacían realidad cuando los niños y las niñas interpretaban las uniones de sus madres como una manera de mostrarles su preferencia por el padrastro. Una situación que desde su lógica representaba abandono y que redundaba en una experiencia de pérdida que despertaba en ellos sentimientos de rechazo y odio. Estos sentimientos en ocasiones eran tan fuertes e intensos que necesitaban mostrarlos a sus madres y hacerlas sufrir por eso mismo. Ricardo me contaba que interpretó la relación que su mamá inició tras abandonar a su padre biológico como una preferencia de su madre por su padrastro, motivo por el que dejó de quererla y por lo que la hacía sentir culpable y sufrir:

Yo no quería a mi mamá. Bueno, al principio la quería, la soñaba, pero cuando me acordaba de los sufrimientos que pasé, se me fue olvidando el cariño que le tenía a mi madre. La culpaba de lo que pasaba en casa y de los problemas que empecé a tener en la calle. Empecé a hacerme fuerte y cruel, y empecé a Cuando la veía por la calle me gustaba hacerla sufrir, me gustaba que me estuviera persiguiendo y que me dijera: “ $\mathrm{iHijo,}$ ven! Ven, Ricardito, quiero estar contigo". Sentía un placer tremendo verla desesperada y pensaba: "Bueno, a mí me tocó sufrir lo que tú me hiciste sufrir". Ella me hizo sufrir porque no me hacía caso, porque prefirió a mi padrastro y porque yo sentía que no me quería. Por eso yo decía: "Bueno, si ella me dejó, ya no la voy a sentir como si fuera mi mamá" (Ricardo, entrevista).

Sonia también me externaba los sentimientos de odio y rencor que le despertaba recordar a su madre. La culpaba de la salida de su casa, pues interpretaba que a partir de la nueva unión descuidó a sus hijas. Sonia no sólo me explicaba su resentimiento y la necesidad de reprocharle a la mamá su comportamiento, también me contaba que su experiencia en calle había contribuido en su proceso de empoderamiento, un poder que en consecuencia la llevaba a no reproducir la situación de sumisión en la que percibía que se encontraba su madre:

Todo lo que yo he logrado, todo lo que yo he hecho, todo lo que he pasado, todo lo que he vivido y todo, todo, todo de mi corta o larga vida que llevo. O sea, ella no ha movido ni un solo dedo por todo esto, ¿no? Sin embargo, a veces me... bueno, me gustaría en un futuro decírselo porque ella prefirió mil veces a mi padrastro que a mí y a mi hermana. Ella era una desmadrosa que no sabía cuidar a sus hijos, sólo pensaba en estar con un hombre, por eso lo mejor era irme de mi casa. Entonces, por eso tengo a veces eso de restregárselo, decirle: “¡Vea, vea por preferir a su esposo!” y “iGracias, gracias!”. En parte sí, a veces sí le estoy agradecida porque gracias a que prefirió a su esposo, gracias a que me hizo a un lado he pasado todo lo que he pasado y gracias a eso no soy una ignorante y sé defenderme. O sea, un hombre o una chava no puede llegar y por sus ovarios quitarme algo por lo que yo he luchado, o sea que si yo de repente me compro un pantalón y de repente me voy a la calle y una chava o un chavo por sus huevos u ovarios me los quiere quitar, o sea: “¿Por qué? ¿Tú quién eres?". Así, aunque me pelee. Y sin embargo, si me hubiera quedado con ella, estuviera llena de hijos y nomás sirviéndole a un machista (Sonia, entrevista).

\section{Escenas de violencia}

En los relatos de los chavos las escenas de violencia dentro de sus familias aparecían como factor que intervenía en la decisión de abandonar sus hogares. La violencia se expresaba y los chavos la sufrían de diversas maneras (Espinosa, 2011: 191). La violencia que presidía los hogares de los niños y las niñas era en ocasiones ejercida por los padres o los padrastros sobre las madres, y en otras por padres, padrastros, madrastras, madres o algún otro familiar sobre los menores. Entiendo la violencia intrafamiliar como una práctica consciente producto de una estructura social basada en la desigualdad, que abarca diversas expresiones. Es el resultado de relaciones desiguales de poder que se ejercen dentro de la unidad familiar y que se construye principalmente sobre las categorías de género y edad. La violencia no sólo implica una forma de control, es también una expresión de dominación y subordinación basada 
en las categorías mencionadas (Espinosa, 2011: 192). Los episodios de violencia que experimentaron los chavales dentro de su unidad familiar eran frecuentemente interpretados como una manera de aplicar la autoridad y disciplina dentro del hogar.

Guadalupe me contaba que en casa de su tía era maltratada por ella y por su marido. La violencia era percibida por esta niña como una manera de establecer las relaciones de obediencia y una forma de ejercer la autoridad (Foucault, 1990). Ella consideraba que los episodios de violencia ocurrían con más frecuencia cuando entre los menores y los adultos no existía una relación de consanguinidad directa, como en el caso su tío. En aquellas situaciones en las que la violencia era ejercida por las parejas de sus padres, padrastros o madrastras, los menores la percibían como una práctica que tenía como finalidad separarlos de sus genitores. Tras encontrar a su mamá en el Distrito Federal y quedarse con ella, para
Guadalupe la convivencia fue imposible porque comenzó a tener problemas con el padrastro, e interpretaba esta situación como una estrategia de éste para echarla de la casa, para que se fuera:

Yo busqué a mi mamá y sí encontré a mi mamá, me fui con mi mamá, pero cuando la encontré, mi mamá ya estaba juntada con el señor aquí en el DF, este señor se llama Pedro. Yo me emocioné mucho, pensaba que mi mamá me iba a recibir bien en la casa. $\mathrm{Al}$ principio sí, pero después empecé a tener problemas con su esposo, con su marido, él me maltrataba. Entonces ella empezó a tener problemas porque el señor no me quería tener en su casa, entonces le decía a mi mamá que él o sus hijos, o si no que se largara (Guadalupe, entrevista).

A su vez, la violencia que sufrían las niñas por el hecho de ser mujeres aparecía en sus discursos como motivo que intervenía en la decisión de salir de

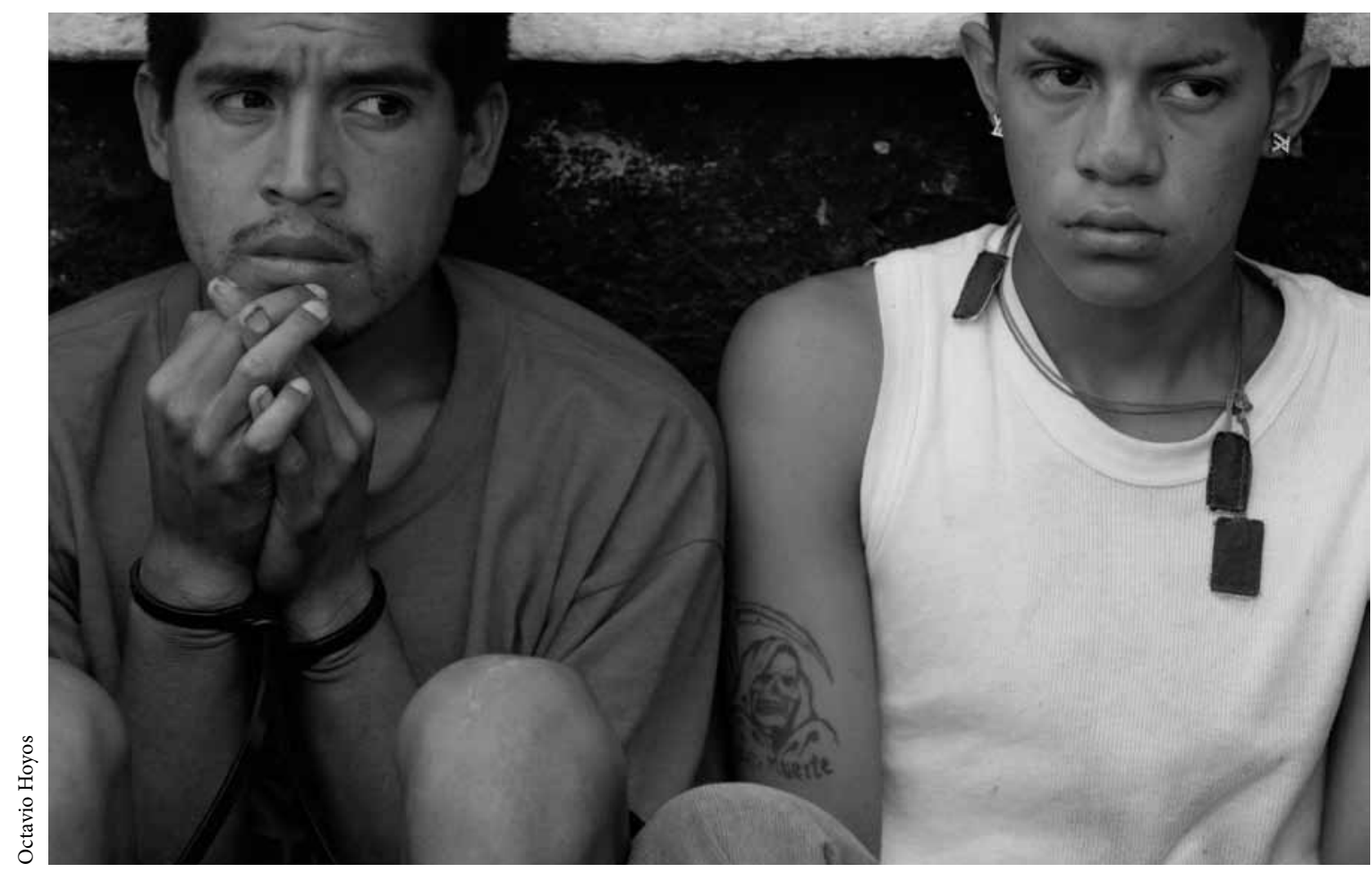

Vecinos del Barrio de Tepito de la ciudad de México detenidos como presuntos narcomenudistas durante cateos realizados en la zona, 2007. 
sus hogares. La violencia emergía a partir de prácticas que conllevaban la desvalorización de lo femenino, invalidando y silenciando formas de comunicación que constituyen estrategias de negación como sujetos sociales (Gregorio, 2006b: 25). Un ejercicio de poder y dominación sobre los cuerpos de las niñas y sobre los significados que tomaban relación con sus discursos (Foucault, 1990). La violencia que los adultos ejercían sobre sus cuerpos, cuando desacreditaban sus palabras, cuando no les creían, anulaban cualquier forma de ejercer el poder. Un poder que hace referencia, como plantea Foucault (1990), a la capacidad de incidir sobre la propia vida y la de los demás, sobre la realidad en la que se inserta la persona:

Prácticas que contribuyen al silenciamiento de las niñas y a modelos de feminidad expresados a través del lenguaje, lo que justifica formas de violencia sobre los sujetos que las encarnan, así como su alejamiento de las posibilidades de incidencia como sujetos de acción (Gregorio, 2006b: 24).

La primera vez que escuché las quejas de las niñas sobre la desvalorización y poco valor de sus palabras fue una tarde en el Hogar Crepúsculo, tras jugar un partido de baloncesto con María, Ana y Sonia. María nos contó que nació en Querétaro, aunque a los seis años se trasladó con su familia a vivir a la ciudad de México. Llegaron a una de las zonas más pobres a las afueras del DF, se llamaba el Charcón. Se instalaron en una habitación que compartían sus padres, sus hermanos y ella. Nos refirió que el hacinamiento era común en esas barriadas, es decir, que varias familias convivieran en una sola habitación, ya que al unirse una pareja los hijos de la mujer - si es que los tenía- pasaban a vivir con ellos. En estas condiciones era frecuente colgar una cortina en medio de la habitación para crear dos espacios: uno para los hijos y el otro para los padres. Nos decía que al no existir intimidad por ser un espacio tan pequeño, muchos adultos aprovechaban para "pasarse de lanza con los más pequeños".
De modo que era habitual que los tíos o los padrastros abusaran de las niñas, y cuando las chicas contaban lo que ocurría casi nunca les creían, siempre le creían al adulto. María relataba:

Si dices: "Es que me hizo esto, me intentó...” “¡Ah, no manches! Tú eres una loca, tú nomás quieres quitármelo, tú eres la que te ofreces". Y como niña, ¿quién te va a creer? (María, entrevista).

Mientras María hablaba, el resto de las chicas asentía. Esa misma tarde, Ana reveló que así había ocurrido en su casa. Ana nació en la ciudad de México. Tras ser abandonada por su papá, su madre tuvo varias parejas. Su último padrastro, con el que su mamá aún convivía, empezó a abusar de ella cuando tenía ocho años, también la maltrataba y nos narró que le "hacía comer la popó" - heces-. Ella le contó todo a su madre y no le creyó y, por el contrario, la regañó y la culpó porque pensaba que ella lo provocaba:

Mis papás se peleaban a cada rato, mi padrastro estaba loco, bebía de vez en cuando y nos pegaba a todos. Él me violaba, yo tenía ocho años y fueron muchas durante mucho tiempo. Me salí de casa porque me había violado mucho y yo sí decía, pero nadie me creía, se lo decía a mi hermana y nada. Mi madre lo sabía y le daba igual. Yo me sentía mal porque mi mamá no hacía nada. Me decía que si me violaba era porque yo me levantaba la falda. Por eso me fui [se echa a llorar] (Ana, entrevista).

\section{Significados de la calle}

Entre los relatos de los chicos y chicas sobre los motivos que los llevaron a tomar la decisión de salir a la calle emergían los significados que le otorgaban a este espacio. El análisis de los significados que toma la calle en relación con el abandono del hogar me lleva a definir este espacio a priori. Entiendo la calle como espacio público donde se llevan a cabo 
actividades productivas y reproductivas. También la interpreto, como propone Del Valle (2002a: 21), "como lugar de resistencia y subversión de los grupos oprimidos donde, a su vez, se expresan los sistemas de género y las relaciones de poder". Las interpretaciones que los chicos y chicas hacían de la calle como lugar de libertad fue una de las explicaciones que me dieron para argumentar su salida. Esta causa, a su vez, aparecía estrechamente relacionada con el proceso de salida y con las circunstancias concretas en sus hogares. Es decir, en aquellos casos en los que los chavales provenían de hogares extremadamente pobres, en los que la violencia formaba parte de la cotidianeidad, la calle era vista como una alternativa a su situación de pobreza y "represión": una manera de acceder a una vida mejor, porque la que tenían no les gustaba. Buscaban en ella la libertad que no tenían en sus hogares, la cual empezaron a experimentar al frecuentar la calle y observar a otros chicos que viven en ella, relacionarse con ellos e imitar sus prácticas. Interpretar la calle como sinónimo de libertad representaba para los chicos y chicas apostar por una vida mejor, que además de permitirles escapar de una situación difícil, en ocasiones dramática, implicaba la ruptura con relaciones adultocéntricas. Es decir, con formas de intervención autoritaria, así como con relaciones asimétricas de poder basadas en la edad (Carli, 2002), mismas que configuran las "culturas adultrocéntricas". ${ }^{6}$

La huida de sus hogares era, por tanto, una práctica, una decisión positiva para los chicos. Inés, por

\footnotetext{
${ }^{6}$ Las culturas adultocéntricas son definidas por Alfageme, Cantos y Martínez (2003: 78) como "modelos de comportamiento desarrollados por culturas dominantes, aplicados al colectivo de la infancia, que no responden a las necesidades reales del grupo". Un ejemplo son los modelos de comportamiento parternalista presentados por Liebel (1994), que distingue entre el paternalismo tradicional, que implica una dependencia y subordinación absoluta de la infancia — aquí son los adultos los que deciden por los niños (Alfageme, Cantos y Martínez, 2003: 78) - y el paternalismo moderno, que cede espacios de acción a los niños y niñas, aunque éstos permanecen a la sombra de los adultos.
}

ejemplo, primero vivió con sus papás en el DF y después tuvo que ir a vivir con sus tíos por la violencia que sufría en su hogar por parte de su papá. Sin embargo, en casa de sus tíos tampoco le gustaba que le mandasen, estaba cansada de tantas normas y decidió abandonarlos. La calle aparecía entonces como la posibilidad de vivir una vida distinta, era un lugar que le ofrecía la oportunidad de ser autónoma:

A una no le gusta que la manden, que una es bien sentida de que aquí hay reglas y de que una se aferra a otras cosas, quiere otras cosas, no quiere que la anden mandando todo el rato. Y pues en la calle no es así. Por eso un día que me peleé bien duro con mis tíos, dije: “¿Sabes? Yo me voy a la calle”. Además, me gusta la libertad. Andar en libertad, de que nadie me diga y mande nada... Eso es lo que me gusta de la calle (Inés, entrevista).

\section{REFLEXIONES FINALES}

Los niños y niñas de la calle tienen una mirada y forma de pensar propias, sobre todo desde el lugar que ocupan dentro de la unidad familiar y sobre aquellas cuestiones que para ellos y ellas son relevantes. Me refiero a las imágenes y creencias que desde su posición de hijos y menores tienen sobre la maternidad, la paternidad y las relaciones materno-filiales. Los discursos muestran la agencia de los niños y niñas, permiten romper esa visión sobre la niñez como dependiente y pasiva. Las imágenes van más allá de representarlos por "su incapacidad para comunicarse, por su filialidad o familiarización - pertenencia a una familia-, por su servidumbre; es decir, dependencia de otro; por su edad" (Cussianovich et al., 2001: 24).

Como se ha podido observar a partir de mi acercamiento etnográfico, los chicos reflexionaban sobre dichas construcciones y emitían una serie de relatos reproduciendo en ocasiones el discurso hegemónico y en otras, cuestionándolo. Las representaciones que muestran la reproducción de la ideología patriarcal dominante, donde las mujeres 


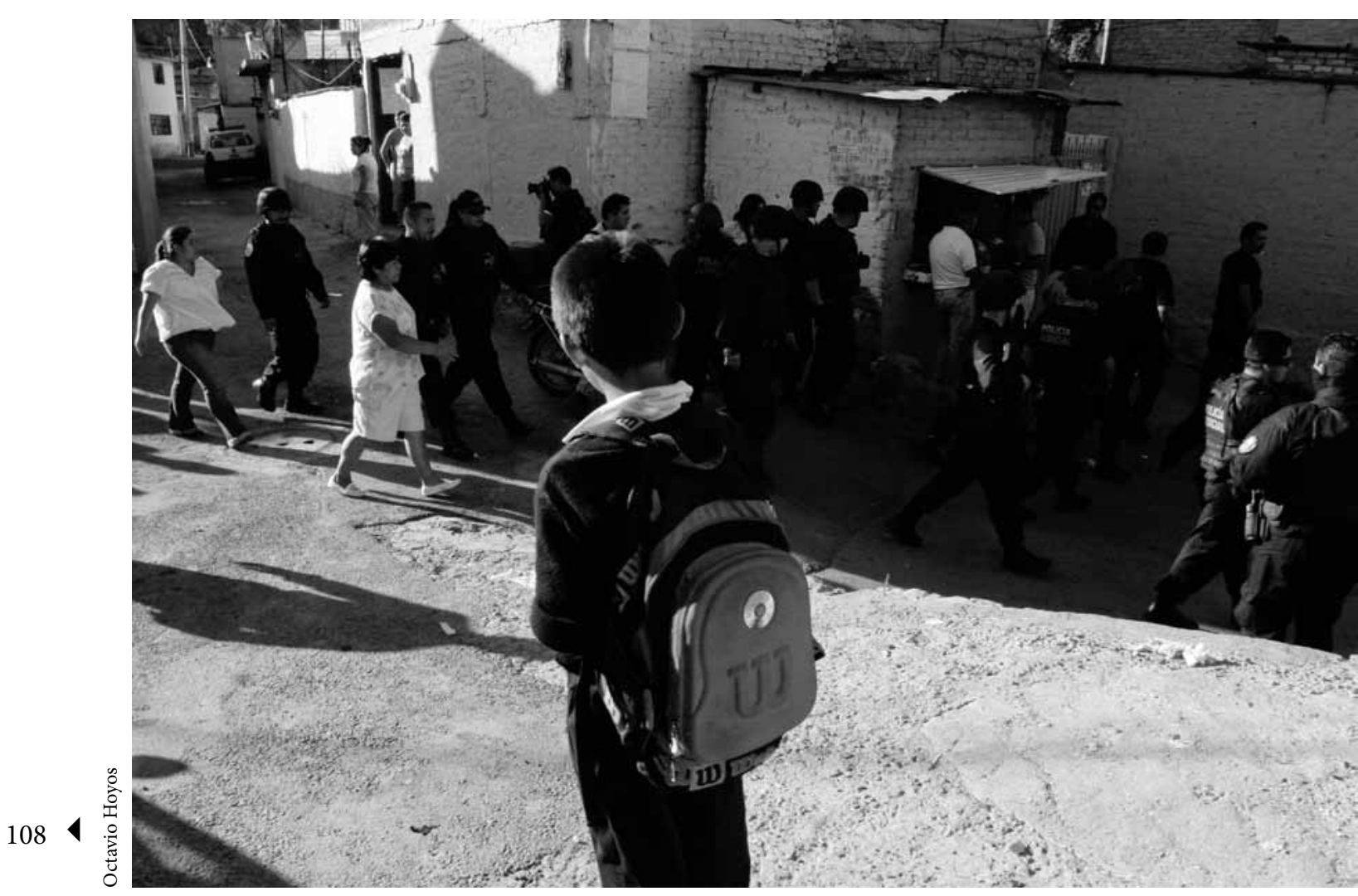

Elementos de policías de diversas corporaciones realizan un operativo en la zona "El Hoyo", en Iztapalapa, ciudad de México, para detener a presuntos delincuentes, 2008.

aparecían censuradas, mal vistas y responsables de la salida de los menores, aparecían frecuentemente cuando las mamás no cumplían con las tareas de reproducción que les habían sido encomendadas socialmente. Por tanto, no responder a tales exigencias como madres conllevaba una serie de prejuicios y descalificaciones por parte de los niños y las niñas, ya que eran consideradas como "malas madres". Esto sucedía principalmente cuando decidían vivir su sexualidad libremente y cuando las expectativas depositadas en las relaciones materno-filiales -que los chicos entendían como naturales por el hecho de ser sus madres y de las que se derivaban una serie de cuidados y protección- no se cumplían. De esta manera, si el punto de partida era el amor, el odio que los niños y niñas sentían hacia sus madres puede entenderse como "un sentimiento producto de la transformación, como alteración del amor" (Del Valle, 2002b: 135). No responder a las expectativas depositadas en esa relación naturalizada generaba en los niños un gran odio y rencor, que en los casos más intensos los llevaba tanto a reclamar a sus madres - en el caso de Víctor y Sonia - como a hacerlas sufrir - en el caso de Ricardo-.

Asimismo, las distintas formas en las que se expresaba la violencia dentro de los hogares de los menores y las diversas maneras en las que las sufrían los chicos y chicas aparecían como factor que intervenía en sus decisiones al momento de salir a la calle (Espinosa, 2006: 191). En este sentido, como sostiene Del Valle (2010: 311), al analizar el trabajo de 
Espinosa (2011) sobre los niños y las niñas en situación de calle en México, "el arma de la violación, de los abusos sexuales en el contexto familiar y los mecanismos, emocionales en unos casos y de miedo en otros, dificultaban que las personas adultas", especialmente sus madres, los evitasen o denunciasen. A su vez, la violencia que las niñas sufrían en sus cuerpos y mensajes anulaban cualquier forma de adquirir y ejercer el poder (Foucault, 1990). Una realidad que contribuía a su silenciamiento, dominación y opresión.

No obstante las representaciones que los menores y jóvenes hacían desde su posición de hijos dentro de una unidad familiar, desde su "pensamiento filial", así como la violencia de que eran objeto, los significados que le atribuían a la calle intervenían en su decisión. Es decir, la lógica que subyace a su representación al interpretar la calle como sinónimo de libertad, el hecho de salir a ese espacio persiguiendo un deseo de cambio, significaba apostar por una vida mejor, lo que suponía además la ruptura con las relaciones asimétricas y adultocéntricas en las que se encontraban. Es así como la calle se convertía en un lugar de producción y reproducción. La huida responde entonces a un proceso muy complejo de significación en el que se articulan las expectativas que los sujetos adscriben al vínculo madre-hijo, la violencia que experimentan dentro del hogar y la pobreza en la que viven. Esta combinación de significados unida a su agencia los lleva a idealizar el espacio público y, lo que es igual, favorece la huida de los niños y niñas de sus hogares. La decisión de salir de su casa puede interpretarse como un acto cargado de valentía, pues implica enfrentarse solos a una realidad compleja y dura como vivir en la calle. Esto me lleva a mostrarlos más allá de la victimización o como sujetos frágiles y vulnerables, para poner de manifiesto su potencial transformador por medio del cual cuestionan, por un lado, una noción de infancia que presenta a los niños y niñas como seres dependientes y pasivos y, por otro lado, las relaciones entre adultos y niños (Espinosa, 2011).

\section{Bibliografía}

Alfageme, Erika, Raquel Cantos y Marta Martínez, 2003, De la participación al protagonismo infantil. Propuestas para la acción, Plataforma de Organización de Infancia, Madrid.

Amuchástegui, Ana, 1996, "El significado de la virginidad y la iniciación sexual. Un relato de investigación”, en Ivonne Szaz y Susana Lerner (comps.), Para comprender la subjetividad. Investigación cualitativa en salud reproductiva y sexualidad, El Colegio de México, México.

Beauvoir, Simone de, 1999, El segundo sexo, Cátedra (Colección Feminismos), Madrid.

Blanco, Ana Isabel et al. (coords.), 2002, Nuevas visiones de la maternidad, Universidad de León, Secretariado de Publicaciones y Medios Audiovisuales, León.

Carli, Sandra, 2002, Niñez, pedagogía y política. Transformaciones de los discursos de la infancia en la historia de la educación argentina entre 1880 y 1995, Miño y Dávila, Buenos Aires.

Chodorow, Nancy, 1984, El ejercicio de la maternidad: psicoanálisis y sociología de la maternidad y la paternidad en la crianza de los hijos, Gedisa, Barcelona.

Cid López, Rosa María, 2002, "Las teorías feministas y la maternidad", en Ana Isabel Blanco et al. (coords.), Nuevas visiones de la maternidad, Universidad de León, Secretariado de Publicaciones y Medios Audiovisuales, León, pp. 11-41.

Cussianovich, Alejandro et al., 2001, La infancia en los escenarios futuros, Universidad Nacional Mayor de San Marcos, Lima.

Del Valle, Teresa, 2002a, “Teoría y etnografía en el estudio de la ciudad: hilos conductores, articulaciones y llaves", en Federación de Asociaciones de Antropología del Estado Español, Actas del IX Congreso de Antropología de la Federación de Asociaciones de Antropología del Estado Español, Cultura y Política, Barcelona.

-, 2002b, "El juego de la memoria en la ritualización del odio”, en Carlos Castilla del Pino (ed.), El odio, Tusquets, Barcelona, pp. 131-147.

, 2010,"La articulación de parentesco y el género desde la antropología feminista”, en V. Fons, A. Piella y M. Valdés (eds.), Procreación, crianza y género, Ediciones PPU, Barcelona, pp. 295-317.

Espinosa, María, 2006, "La vida en las calles de la ciudad de México. Una misma calle con realidades distintas", en Actas del Congreso Internacional de Estudios de Género y Políticas de Igualdad. Indicadores de Género y Estado de Bienestar, vol. 2, Instituto Andaluz de la $\mathrm{Mu}$ jer, Sevilla, pp. 189-202. 
2009, "Los 'chavos banda' como forma de organización alternativa a la familia entre los menores en situación de calle", en Gazeta de Antropología, núm. 25 , pp. 1-18.

, 2010, "La articulación del parentesco y el género desde la antropología feminista”, en Virginia Fons, Anna Piella y María Valdés (eds.), Procreación, crianza y género, Ediciones PPU, Barcelona, pp. 295-317.

— , 2011, "Mi banda, mi hogar". Resignificando la infancia a partir de los niños y niñas de la calle de la ciudad de México, Editorial Académica Española, Granada.

Foucault, Michel, 1990, Tecnologías del yo, Paidós, Barcelona.

González de la Rocha, Mercedes, 1999, "Hogares de jefatura femenina en México: patrones y formas de vida", en Mercedes González de la Rocha (coord.), Divergencias del modelo tradicional: hogares de jefatura femenina en América Latina, Plaza y Valdés, México, pp. $125-151$

Gregorio Gil, Carmen, 2006a, "Contribuciones feministas a problemas epistemológicos de la disciplina antropológica: representación y relaciones de poder", en $A I B R$,
Revista de Antropología Iberoamericana, Asociación de Antropólogos Iberoamericanos en Red, vol. 1, núm. 1, enero-febrero, pp. 22-39.

, 2006b, "Violencia de género y cotidianidad escolar", en Estudios, núm. 23, Instituto Andaluz de la $\mathrm{Mu}$ jer, pp. 1-89.

Lamas, Marta, 1996, "La antropología feminista y la categoría género", en Marta Lamas (comp.), La construcción cultural de la diferencia sexual, Universidad Nacional Autónoma de México, México, pp. 97-125.

Liebel, Manfred, 1996, "El protagonismo infantil organizado de los niños y niñas trabajadores", en Movimiento de Niños, Niñas y Adolescentes Trabajadores de Nicaragua, Sobre protagonismo infantil: materiales de estudio, Movimiento de Niños, Niñas y Adolescentes Trabajadores de Nicaragua (Cuadernos Natras, núm. 4), pp. 5-25.

Maier, Elizabeth, 1999, "El mito de la madre”, en Iztapalapa, núm. 45, México, pp. 9-106.

Milstein, Diana, 2006, “¿Y los niños por qué no? Algunas reflexiones sobre un trabajo de campo con niños", en Avá, núm. 9, pp. 49-59. 